\title{
Using Citizen Science to Help Monitor Urban Landscape Changes and Drive Improvements
}

Karin Wannemacher', Barbara Birli', Tobias Sturn², Richard Stiles³, Inian Moorthy2, Linda See ${ }^{2}$ and Steffen Fritz²,

'Environment Agency Austria

2International Institute for Applied Systems Analysis, Austria

3Vienna University of Technology, Austria

\begin{abstract}
Citizen Science has become a vital source for data collection when the spatial and temporal extent of a project makes it too expensive to send experts into the field. However, involving citizens can go further than that - participatory projects focusing on subjective parameters can fill in the gap between local community needs and stakeholder approaches to tackle key social and environmental issues.

LandSense, a Horizon 2020 project that is deeply rooted in environmental challenges and solutions, aims to establish a citizen observatory that will provide data to stakeholders, from researchers to businesses. Within this project, a mobile application has been developed that aims not only to stimulate civic engagement to monitor changes within the urban environment, but also to enable users to drive improvements by providing city planners with information about the public perception of urban spaces. The launch of a public version of such an app requires preparation and testing by focus groups. Recently, a prototype of the app was used by both staff and students from Vienna University of Technology, who contributed valuable insights to help enhance this citizen science tool for engaging and empowering the inhabitants of the city.
\end{abstract}

\section{Keywords:}

LandSense, citizen observatory, urban geoinformatics, green urban space, citizen science

\section{Introduction}

Citizen science is the involvement of the general public in scientific research, which can include passive sensing and crowdsourcing at the lowest level, data collection, analysis and interpretation of the data at higher participatory levels, and the co-creation of research projects at the highest level (Bonney et al., 2009; Haklay, 2013). There are many examples of successful citizen science projects, e.g. Galaxy Zoo, which involves citizens in the classification (and discovery) of galaxies (Raddick et al., 2007), and eBird, which has tapped 
into existing bird watching communities (Sullivan et al. 2009). Like the majority of citizen science projects, Galaxy Zoo and eBird involve citizens mainly in data collection.

Within LandSense, a project that combines Earth Observation (EO) with other innovative methods of data collection, a mobile application for monitoring green spaces and gathering public perceptions of them is being developed. To test the proposed approach, a trial run was conducted with students of Vienna University of Technology as part of their regular course units. The aim was to test usability and establish a benchmark regarding the quality of the data that can be expected, before an app for public use was designed. It was also important to see whether the participants thought that products derived from their subjective data properly reflected their in-situ perceptions of the places. Based on the feedback from students and staff, the concept for an app for use by the wider public was revised and adapted.

\section{LandSense}

Low-cost methods for the timely acquisition of in-situ validation data are very valuable when combined with satellite-based imagery to create accurate and reliable environmental monitoring products. The Geo-Wiki project is an example of a citizen science activity focused on involving citizens in the classification of satellite imagery to improve land-cover and land-use maps (Fritz et al., 2012). It is one of the tools of the EU-funded LandSense Citizen Observatory, which integrates EO technologies, mobile devices, community-based environmental monitoring and data collection, interpretation, and information delivery systems to empower communities to monitor and report on their environment. Collaborations with local government highlight the value for decision-making and policy relevance of conflating citizen-driven, in-situ observations with traditional authoritative and open access data sources.

Within the LandSense project, there are three main domains of land monitoring, one of which addresses urban landscape dynamics. This domain focuses on engaging citizens in monitoring land-use change in urban and peri-urban areas to support local decision-makers in urban monitoring and planning. In Vienna, the LandSense project is working with the city administration to monitor the urban environment, particularly with respect to green spaces and the public perception and use of urban spaces.

The city has created an urban development plan for its future that combines smart-city approaches with social and cosmopolitical ambitions. Within the city's agenda for 'giving residents more of a say in the development of open spaces', the following points are particularly important:

- Co-operation with the population to develop optimized and viable urban solutions

- Strengthening and further developing networks of green and open spaces

(STEP 2025, 2014).

This aim will be supported by an app which is being developed within the LandSense project. Besides creating new open spaces and recreational areas, the city is working on 
establishing green corridors, creating a network of green spaces dubbed the 'Frei.Raum.Netz' [= 'open.space.network'], which will form the basis of the app.

\section{Approach}

The mobile application follows a combination of top-down and bottom-up approaches (Balestrini et al., 2017). While it clearly aims to provide the city administration with the desired local insights into changes in the urban landscape, it also enables its users to influence city development and certain selective improvements in particular. As a stakeholder in this project, MA18 (the city of Vienna's department for urban development and planning) is keen to garner citizen feedback and has already launched another app, 'Sags Wien', which enables users to alert a maintenance team if they spot, for example, broken streetlamps, rubbish, etc. While 'Sags Wien' is focused, ideally, on quickly resolving minor problems, the 'Frei.Raum.Netz' app focuses on personal perceptions of key locations across the city, which then feed into long-term city planning.

The application used for the trial run is a modified version of the FotoQuest Go app. The mobile application for the public is being developed by the LandSense team.

\section{Test case using architecture students}

The test group were architecture students from the Vienna University of Technology (TUW), who in the context of the course unit 'Introduction to Landscape Architecture' had to explore pre-defined areas of the city. These areas were selected as sites currently undergoing major planning/reconstruction work, and parts of all of the areas are included in the 'Frei.Raum.Netz'.

Working with the app was one of the many tasks the students were asked to carry out, with the goal of discovering the open-space structure of a modern city and the way this interacts with the built fabric. The exercise with the app was designed to make students consciously look away from buildings, and explore specific characteristics of the city's open spaces.

Working in teams of 3 , the students were asked by the application to visit a set of predefined points (to which the app also directed them) within their designated study areas. Each location could only be visited once and quests could only be performed once. 

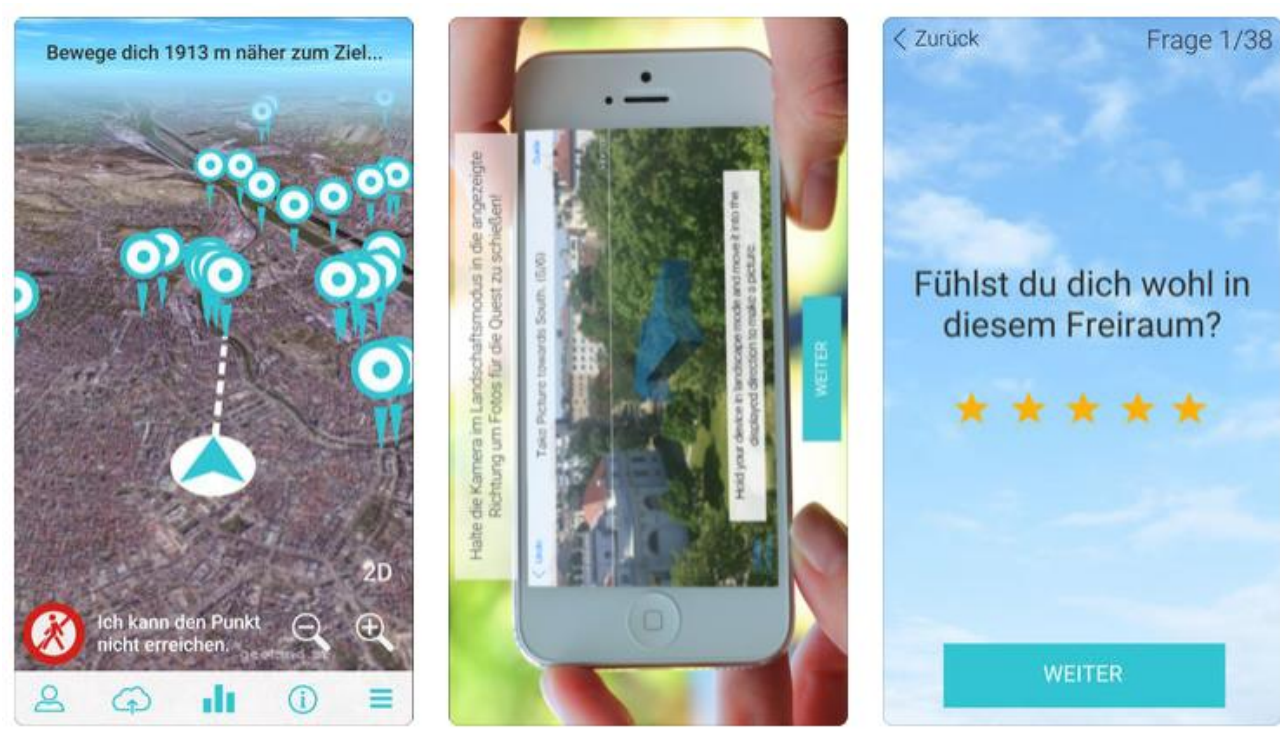

Figure 1: Screen shots of the 'Frei.Raum.Netz' app

If a destination cannot be reached, for example if the point is in the middle of a body of water or of a busy road, users can indicate 'location inaccessible' within the application. Once the user has reached the location, he/she is guided through a protocol to acquire photos in the four cardinal directions, before answering a series of questions (see Figure 1). To respect privacy rights, the app includes functions that enable users to blur out people or licence plates in the photos.

The questionnaire was compiled by the Department of Landscape Architecture at the TUW within the context of the course unit in such a way as to combine the aims of the class with a valid classification of the space, based on factual information, subjective impressions and emotional data. The set of questions about subjective perceptions included ones about safety, noise, smells, sounds and the overall perception of the space. Other categories were 'Use' (who uses the space, what people are doing, surrounding infrastructure), 'Ecology and Climate' (vegetation and its condition, wildlife, ...) and 'Structure' (accessibility, surface covering, access to transportation network, ...).

\section{Results of the test case}

Students were scheduled to complete their assignments between October 2017 and January 2018. Although this period is not ideal for the observation of vegetation and its effects on the surrounding area or the use of open spaces in general, observations made during October could have provided acceptable data. However, hardly any data was collected in early October. A third of the students completed the task by the end of $2017.60 \%$ of the finished quests were submitted in January.

Spatial analysis of the subjective data indicates that in some instances the subjective data correlated significantly with the city's structure. While 'Frei.Raum.Netz' is largely 
independent of the main road network, there are some areas where it runs along the city's main thoroughfares. The reported noise levels were higher in urban spaces that bordered on major roads, and during the test period the screening effect of vegetation could not be experienced to the full.

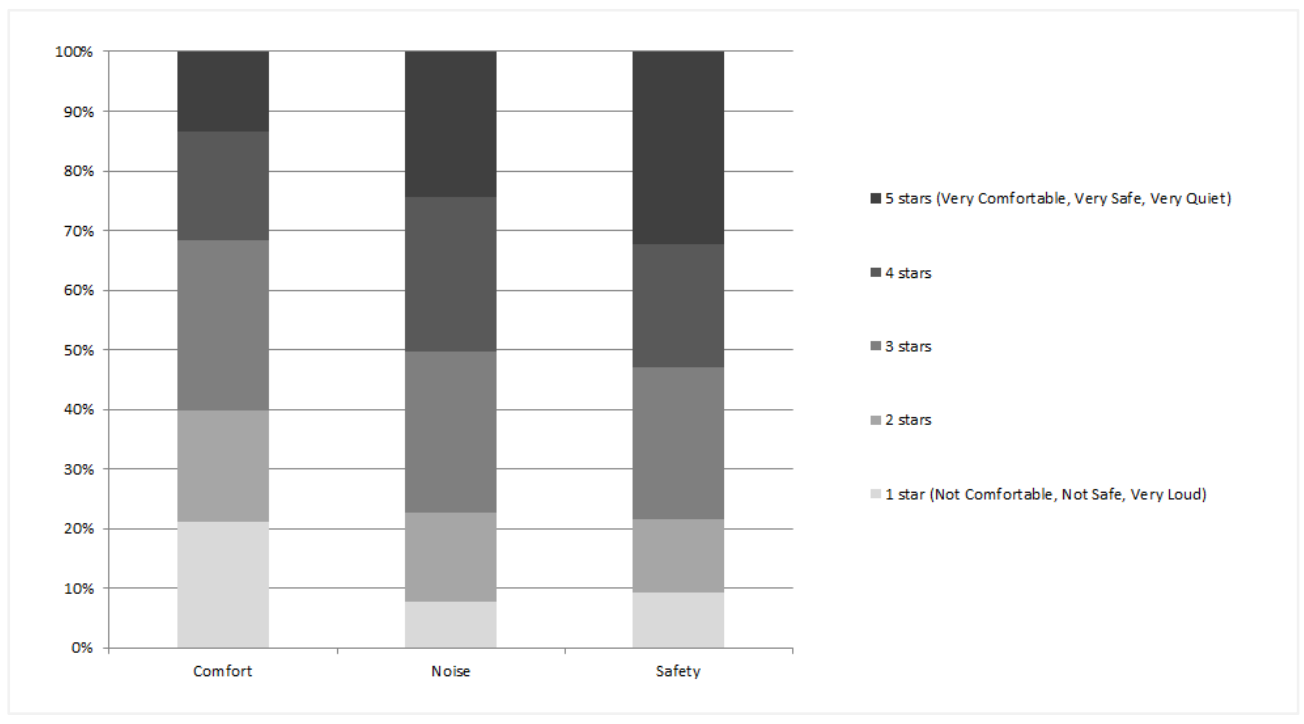

Figure 2: Overall results of the subjective perception

Figure 2 shows a summary of the subjective data ratings regarding the perception of Noise, Safety and General comfort, for all the data submitted. The results imply a largely positive attitude towards the places visited.

There are several factors that could have influenced the rating, not least whether the students liked working with the app. Furthermore the study points assigned to them were within parts of the city where the students were working for the whole semester. It might be surmised, therefore, that the students formed a positive relationship with 'their' study areas, possibly influencing the objectivity of the results. 


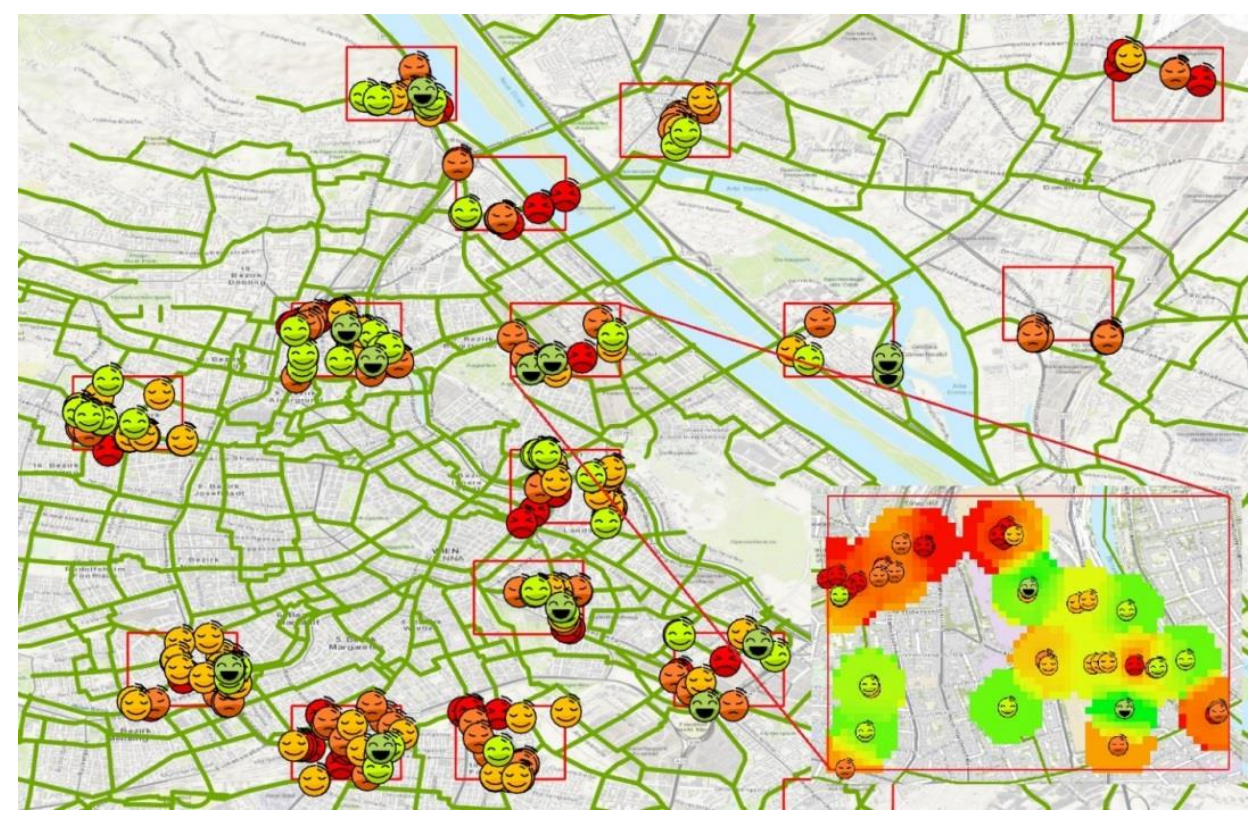

Figure 3: Screen shot of the 'emotion map' and 'Frei.Raum.Netz'

The teams of students from the University of Technology provided the test case with 378 observations in the 'Frei.Raum.Netz' app. To give them visual feedback on their work, the data was translated into an emotion map (Figure 3). Students could choose between a 'smiley map' or interpolated results of the subjective classification of noise, safety or comfort. A brief summary of the data collected for each observation point and a gallery of the pictures they took were also provided.

\section{Student and faculty feedback}

Students were asked to provide voluntary feedback about the the usability of the application and of the derived product, the emotion map, as part of their assignment. This voluntary evaluation was done through both conversations with the students and an online questionnaire. Despite offering some incentives, only 12 students completed the online form. They described the app and its features as mostly easy to use, and all agreed that it was not difficult to find the quest points, although there was some confusion as to how big the observed quest area was. All but 3 users were positive about a public version of the app. Data displayed in the emotion map was a good reflection of their impressions of the sites.

The students insisted that the application must add more value for the user if it is to gain popularity. Specific suggestions were gamification, treasure hunts, or being able to find the nearest park bench.

In general, the benefits of the app for the TUW course were that it helped to formalize and structure the otherwise more general instructions to students about how to analyse aspects of their study areas, in particular their subjective reactions to the green- and open-space components of the city. 


\section{$4 \quad$ Public App}

Based on the results of the test run, the design of the public version is now underway. The public application will make it possible for locations to be visited more than once to ensure that the space is observed over a long period, and to provide context for the other data collected in that area. A shortened questionnaire will focus on subjective perceptions (overall perception, noise and safety), nature and wildlife.

The feedback clearly indicated that additional benefits for the users are vital to attract participants.

An additional feature will focus on the ways open spaces are used for activities, based on 7 main categories (standing, sitting, lying, playing, walking, sport, other activities). Data from this feature will make it possible for users to look up suitable locations (e.g. a place to sit or play ball). This functionality is designed to be the Unique Selling Point of the public app.

A trial with the redesigned app was scheduled for April 2018, with students from the University of Natural Resources and Life Sciences of Vienna.

\section{Discussion}

With 378 points in Vienna visited by some 173 users, the test run was satisfactory. The level of participation was a success, but was an integral part of a required course for the architecture students. Recording at least 3 points was compulsory for students in order to successfully complete the course unit in question, so this guaranteed a certain level of participation. However, some visited far more than the minimum required, with some students visiting up to 10 points. This suggests that a certain interest in the app had been generated, and maybe the high score list, an additional feature of the application, added further to this.

The stakeholders thought that the data collected was useful. However, the value and significance of the data need to be improved by collecting answers from different people and during different times of the year and day, something that the project team wants to achieve with the application for the wider public.

\section{Conclusion}

The test case using students and staff from Vienna University of Technology contributed significantly to the redesign of the public app. Only through on-site use by a large number of participants were the app's strengths and weaknesses revealed.

The real value of the app is likely to be twofold: firstly, to help sensitize the general public to the qualities of the open spaces which are an integral part of their daily environment, but which often go unnoticed in the rush of everyday life; second, the collection of data on how open spaces are used and perceived by citizens from a variety of perspectives can provide 
useful information for those involved in the planning, design and management of the spaces. Awareness of the critical importance of the network of green and open spaces within urban areas has increased over recent years with the development of concepts such as 'green infrastructure' and 'nature-based solutions' as ways of ameliorating the impacts of climate change, as well as increasing the attractiveness and livability of towns and cities as urban areas continue to grow world-wide.

\section{Acknowledgement}

This work was supported by the EU-funded Horizon2020 LandSense project under Grant 689812.

\section{References}

Balestrini, M., Rogers, Y., Hassan, C., Creus, J., King, M., \& Marshall, P. (2017). A city in common: a framework to orchestrate large-scale citizen engagement around urban issues. In Proceedings of the 2017 CHI Conference on Human Factors in Computing Systems (pp. 2282-2294). ACM.

Bonney R., Cooper C. B., Dickinson J., et al. (2009) Citizen science: A developing tool for expanding science knowledge and scientific literacy. BioScience 59:977-984. doi: 10.1525/bio.2009.59.11.9

Fritz S., McCallum I., Schill C., et al. (2012). Geo-Wiki: An online platform for improving global land cover. Environ Model Software(?) 31:110-123. doi: 10.1016/j.envsoft.2011.11.015

Haklay, M. (2013). Citizen science and volunteered geographic information: Overview and typology of participation. In Sui D., Elwood S., and Goodchild M. (eds), Crowdsourcing Geographic Knowledge. Dordrecht: Springer, pp 105-122

Raddick, J., Lintott, C. J., Schawinski, K., Thomas, D., Nichol, R. C., Andreescu, D., ... \& Szalay, A. S. (2007, December). Galaxy Zoo: an experiment in public science participation. In Bulletin of the American Astronomical Society (Vol. 39, p. 892).

STEP 2025 (2014). STEP 2025, Urban Development Plan Vienna. Retrieved from https://www.wien.gv.at/stadtentwicklung/studien/pdf/b008379b.pdf

Sullivan, B. L., Wood, C. L., Iliff, M. J., Bonney, R. E., Fink, D., \& Kelling, S. (2009). eBird: A citizenbased bird observation network in the biological sciences. Biological Conservation, 142(10), 2282 2292. 